pp. $501-520$

\title{
Long-Term, Short-Term and Time-Varying Profitability of Reversals: The Role of Market State and Volatility
}

\author{
Submitted 08/01/20, $1^{\text {st }}$ revision 14/02/20, $2^{\text {nd }}$ revision 24/03/20, accepted 16/05/20
}

\author{
Ali Fayyaz Munir ${ }^{1}$, Shahrin Saaid Shaharuddin ${ }^{2}$, Mohd Edil Abd. Sukor ${ }^{3}$
}

\begin{abstract}
:
Purpose: The purpose of this paper is to investigate the various patterns of contrarian trading strategy that can generate superior returns for retail investors in Pakistan Stock Exchange (PSX).

Design/Methodology/Approach: To examine the long-term and short-term pattern of contrarian anomaly, the study adopts the buy-and-hold method and $j$ - $k$ overlapping portfolio formation procedure of Jegadeesh and Titman with slight modifications. Moreover, the study is also carried out to investigate the relation between the performance of contrarian portfolios and several market conditions to further test if the time-varying contrarian effects are context-dependent.

Findings: The study findings suggest the existence of both long-term and short-term reversal effects that vary over time. Interestingly, the contrarian strategies yield higher returns during crisis periods, negative market state and higher market volatility. We show that short-term reversals, thus the payoffs to contrarian strategy, are predictable with market state which is found to be the primary predictor. The overall findings of this research lend partial support to the Adaptive Market Hypothesis (AMH) which claims that the changed stock market conditions are the main causes of time-varying behavior of market efficiency.

Practical Implications: The existing literature reveals that the unchecked stock market intermediaries in PSX artificially manipulate the stock prices and earn abnormal returns at the expense of momentum or uninformed investors. The current research enables the policy makers and regulators to understand why emerging equity markets fail due to manipulations and how unsheltered investors can survive under the weak governing environment.

Originality/Value: This study contributes to the existing literature on asset pricing by innovating various ways of excess returns based on contrarian trading strategy. In addition, our work contributes to the literature on the AMH by testing the impact of several stock market conditions on the time-varying profitability of contrarian strategy. There is a dearth of literature on the conditioning impact of various market states on the time-varying behavior of trading strategies in emerging markets.
\end{abstract}

Keywords: Emerging markets, contrarian theory, contrarian payoffs, EMH, AMH, market hypotheses.

JEL codes: G14, G15.

Raper type: Research article.

\footnotetext{
${ }^{1}$ University of Malaya, Malaysia, e-mail: muniralifayyaz@gmail.com

${ }^{2}$ University of Malaya, Malaysia, e-mail: shahrin@um.edu.my

${ }^{3}$ University of Malaya, Malaysia, e-mail: $\underline{\text { mohdedil@um.edu.my }}$
} 


\section{Introduction}

In emerging markets, the issues relating to the governance of stock market intermediaries and enforcement of laws and regulations have gained importance (Glaeser, Johnson, and Shleifer, 2001; La Porta, Lopez-De-Silanes, and Shleifer, 2006). It is strongly believed that the legal and institutional framework of the emerging equity markets should be well-developed and improved. This helps in generating long-term funds for corporations, banks, and governments. Moreover, such design stimulates the efficient allocation of resources in which the funds are collected from small investors and used in the riskier or more valuable projects. The risk diversified portfolio can be developed for investors by using such design which will increase their risk-sharing ability. However, the legal, institutional and economic framework of Pakistan does not help in improving the market growth. The price manipulation by several stock market intermediaries restricts the growth in market capitalization as the individual investors feel fear to invest in this market.

The colluding brokers ${ }^{4}$ earn abnormal returns at the expense of positive feedback or momentum traders in the Pakistan stock exchange (PSX). The findings of existing literature reveal that unchecked intermediaries in PSX artificially manipulate the stock prices by "pump" and "dump" schemes and earn about 50 to 90 percentage points higher than outside investors (Khwaja and Mian, 2005; Azad, Azmat, Fang, and Edirisuriya, 2014). During the pumping phase of manipulation, these colluding brokers trade the stocks among themselves in order to artificially inflate the stock prices and attract positive feedback or momentum traders. When prices rise, the brokers left the market and later party (retail investors) suffer the losses of ensuring price fall. In these circumstances, there is a need to investigate a suitable investment strategy for retail investors which can yield excess returns under the manipulative and inefficient environment of PSX.

The existing literature mostly documents the success of momentum strategies in the U.S and other developed equity markets (Rouwenhorst, 1998; Grundy and Martin, 2001; Lewellen, 2002; Hart, Slagter, and Dijk, 2003; Grinblatt and Moskowitz, 2004; Fama and French, 2008, 2012; Asness, Moskowitz, and Pedersen, 2013; Wang and $\mathrm{Xu}, 2015)$. However, as per highlighted problem regarding unchecked pumpand-dump manipulations in South-Asian emerging markets like PSX, the momentum strategy seems unsuccessful (as uninformed momentum investors suffer a loss due to unhealthy price manipulations). So, the primary objective of this research is to identify the various patterns of contrarian trading scheme that can generate superior returns for retail investors.

The explanation for contrarian and momentum anomalies varies across equity markets while the significance level of anomalous profits from such investment

\footnotetext{
${ }^{4}$ The stock market intermediaries that make a cartel and artificially manipulate the stock prices to attract the uninformed momentum investors.
} 
strategies also differs across time (Asness, Frazzini, Israel, and Moskowitz, 2015). From the past few years, EMH has been receiving criticism due to its failure in explaining the returns of market anomalies (for instance contrarian and momentum). In most recent times, the researchers are looking to examine the stock market efficiency across markets and over time, rather than seeing market efficiency as a phenomenon of the same for all. In this context, Lo (2004) suggested the latest market efficiency theory named Adaptive Market Hypothesis (AMH), which states that the market efficiency varies across markets and over time. Momentum and contrarian anomalies always represent the departures from the stock market efficiency. This divergence from stock market efficiency and a further extension in the stock anomalies behavior due to changing market environment may provide justifications for the existence of such anomalies.

Furthermore, the latest calendar anomalies researches (Urquhart and McGroarty, 2014) reveal that the seasonal changes justify the prevalence of AMH in the US market while the changing market conditions can explain these seasonal effects. Cooper, Gutierrez, and Hameed (2004) analyze the effectiveness of momentum strategy during the "up" and "down" equity market states and find that significant momentum returns prevail primarily in the "up" state. Huang (2006) further, confirms a similar finding in a broader international setting. The current research also investigates the contrarian effect under varying stock market states in order to examine whether the changed market conditions, which is also the main argument of $\mathrm{AMH}$, can explain the time-varying nature of contrarian effect in PSX.

The empirical findings suggest the existence of both long-term and short-term reversal effects that vary over time. The contrarian trading strategies with long-term buy-and hold method and short-term overlapping portfolio formation procedure confirm the presence of statistically significant contrarian effects in PSX. The results are robust under the sub-period holding analysis which also confirms the nonexistence of the impact of seasonality/January anomaly on contrarian returns. Interestingly, contrarian strategies yield higher returns during the negative market state, higher volatility and crisis periods. However, the market state effect is more dominant as compared to market volatility (Thalassinos et al., 2015). This finding contradicts the results of Wang and $\mathrm{Xu}$ (2015), who find that the volatility absorbs most of the explanatory power for momentum payoffs in a more developed US market. From an investment perspective, our findings suggest that a contrarian strategy, conditional on the market state, could be employed within a managed fund in order to generate abnormal profits that cannot be earned by conventional models.

The current research has several contributions. First, in South-Asian emerging markets, the mean reversion of stock prices, non-randomness of returns and speculative and manipulative bubbles are common phenomenon (Azad et al., 2014). Hence, the sample selection from one of these emerging markets like PSX has an added significance for current research. As these emerging markets show a smaller degree of association with the other developed and frontier equity markets (Harvey, 
1995), the empirical investigation from such markets provides further validation to the theory that the findings are not merely due to a higher correlation with samples from previous studies.

Second, the empirical findings on contrarian effect, in emerging markets context, seem to present a variety of justifications for the existence of contrarian anomaly. Especially, examining whether the profitability and statistical significance of anomaly returns depend on time-varying market conditions in PSX, this research finding can offer support to the Adaptive Market Hypothesis (AMH), which will bridge some gap between the varying explanations of the proponents of EMH and the behavioral school of finance. Furthermore, the examination of time-variant behavior of contrarian anomaly, and whether the investors from the emerging markets adapt towards changing market conditions like the investors in developed markets, the research findings can shed light on the debate of AMH whether market efficiencies and inefficiencies coexist in PSX.

Third, by examining whether the higher anomalous profits of contrarian strategy are mainly due to the behavioral tendencies or time-varying factors, this research will provide different evaluation matrices to fund managers and investment communities. The investors who are sophisticated enough and follow the contrarian investment strategies instead of momentum strategies in emerging markets like PSX, can generate higher anomalous profits based on their superior information about the price manipulation tactics of unchecked intermediaries.

The rest of this paper is arranged as follows: Section 2 provides a review of the literature regarding previous studies, section 3 explains the data and methodology used in this research. Section 4 provides empirical findings and discussions and section 5 finally concludes the paper.

\section{Literature Review}

The Efficient Market Hypothesis (EMH) is a parameter that many investors apply while making investment decisions. The more quickly a stock market incorporates the new information, the more efficient that market is. The proponents of EMH deny the possibility of consistent abnormal returns in an efficient capital market. However, the validity of EMH has not been established due to its profound implications. Various stock market anomalies challenge the foundations of EMH due to the existence of speculative behavior in stock markets. Meier (2014) describes several types of capital market anomalies. He revealed that some of these anomalies still exist (e.g. Momentum and Contrarian), but some (e.g. January, size and day-ofthe-week effect) are slowly disappearing. Momentum and Contrarian are the two well-known anomalies of asset pricing that work under the weak form of market inefficiencies. 
Malkiel (2003) provides his study on "The Efficient Market Hypothesis and Its Critics" in which he states that "Undoubtedly, some participants of the market are less than rational". Due to this, the predictable patterns in stock returns and pricing irregularities appear that last for a shorter period. Furthermore, the stock markets are not fully efficient; otherwise, the professionals have no motivation to reveal the available information that is quickly reflected in prices. Lo and MacKinlay (1988) examine the US equity market index and find weak serial correlation in a shorter time-period stating that the positive previous returns lead to positive recent returns. Moreover, the US stocks show momentum (continuation) effects in intermediate time-horizons such as 3-12 months as reported by Jegadeesh and Titman (1993).

The existence of reversal and continuation effects suggest that abnormal returns can be exploited based on momentum or contrarian investment strategies. A zero initial investment portfolio can be constructed with short selling proceed by assuming transaction cost as zero. The studies of Parhizgari and Nguyen (2008) find the momentum and contrarian effect in American Depository Receipts Market (ADRs). The presence of contrarian or momentum profits has also been found in Non-US Countries. De Haan and Kakes (2011) examined the profitability of various trading schemes for Dutch institutional investors i.e., life insurers, non-life insurers, and pension funds over the period from 1999 to 2005. The overall results reveal that among three types of traders, pension fund managers usually follow contrarian investment strategies. Many other studies found momentum profits in the U.S equity market (Grundy and Martin, 2001; Grinblatt and Moskowitz, 2004; Fama and French, 2008).

Muga and Santamaría (2007) conducted their research on equity markets of Latin America and they found that momentum investment strategies earn excess returns in these markets. The findings also suggest a stronger momentum effect in Latin America as compared to other developed markets. The studies of Ramiah, Cheng, Orriols, Naughton, and Hallahan (2011) and Bernstein, Lerner, and Schoar (2013) are also consistent with the above findings of stock market investment strategies. Doan, Alexeev, and Brooks (2014) study the behavior of the Australian equity market to examine the coexistence of contrarian and momentum profits. They concluded that the contrarian effect dominates in the short-term investment period while the momentum effect prevails in both long-term and intermediate-term investment horizons. Overall, the existing literature exhibits that momentum strategies dominate in more developed and well-governed stock markets.

However, specifically for Asian Stock markets, the studies find weak-form market inefficiencies with a very low momentum effect (e.g. Chui, Wei, and Titman, 2000; Griffin, Ji, and Martin, 2003; Shah and Shah, 2017). Chui et al. (2000) primarily analyzed the momentum trading effect in eight (8) Asian equity markets from the period 1978 to 2000 . They formed 6-6 month's relative strength strategies with a threshold of top and bottom $30 \%$ as winner's and loser's stocks, respectively. They find a very low momentum effect in the Asian equity markets, significant only in the 
case of Hong Kong, which is considered a relatively developed equity market within the Asian region. Griffin et al. (2003) study the momentum effect worldwide by forming 6-6 strategies based on the data of the following regions: The United States, Asia, Africa, and Europe. In this strategy, the stocks are sorted in a portfolio based on past 6-month returns and held further for next 6-months. They find moment trading profits in almost all the regions except Asia where the effect was very weak. $\mathrm{Yu}$, Fung, and Leung (2019) also find the same trend in three Chinesse stock markets namely Shenzhen Stock Exchange (SZSE), SZSE Growth Enterprise (GEM) and Shanghai Stock Exchange (SSE). Hameed and Ting (2000) report the short-term contrarian profits in the Malaysian equity market while Locke and Gupta (2009) find contrarian trading returns in the Indian equity market. Thalassinos and Thalassinos (2006) and Thalassinos et al. (2006) found integration and market inefficiency in the Greek stock market.

The empirical evidence supports a strong contrarian (reversal) effect in South-Asian equity markets. Within the Asian region, the South-Asian stock markets like India, Pakistan and Bangladesh are mostly dominated by noise traders and small investors. This noise trading contributes towards enhanced risk in a shorter time horizon (Cuthbertson and Nitzsche, 2005), while the investment decisions of such small investors are usually driven by either sentiments or past movements in share prices (Shiller, 1990). These equity markets further express the unique structural and psychological differences as compared to developed equity markets (Chui et al., 2000). Based on these structural and psychological differences, consistent with the existing literature, these markets behave opposite to developed markets and usually show contrarian effect which produces unique intuitions regarding the stock market anomalies returns. Therefore, we expect that the various time-varying patterns of contrarian trading strategy can generate superior returns for retail investors in PSX. There is dearth of literature on the conditioning impact of various market states on the time-varying behavior of contrarian payoffs in the Pakistani stock market.

\section{Data and Methodology}

\subsection{Data}

The dataset comprises of monthly dividend-adjusted prices of all the firms listed on the Pakistan Stock Exchange (PSX) obtained from Thomson and Reuters DataStream. The study period extends from January 1999 to December 2018. The main aim of selecting this research period is to test the investment strategies in different stock market regimes like bullish, bearish, stock market bubbles and crisis. To mitigate the effect of least liquid and inconsistent stocks, we exclude those shares that have an irregular trading history. KSE 100 index is the main index of PSX which is considered as the market risk proxy in this research. The index returns are further utilized to generate the variables of market states and volatility for further econometric analysis. The monthly dividend-adjusted prices of all the selected 
stocks and market index are converted into monthly returns by using the following formula of continuous compounding returns:

$$
R_{t}=100 \times \ln \left(\frac{P_{t}}{P_{t-1}}\right)
$$

where,

$\mathrm{R}_{\mathrm{t}}=$ the monthly return of a stock or market index;

$\mathrm{P}_{\mathrm{t}}=$ the monthly closing price of a stock or market index adjusted for dividend at time t;

$\mathrm{P}_{\mathrm{t}-1}=$ the monthly closing price of a stock or market index adjusted for dividend at time t-1.

\subsection{Methodology}

We use the methodologies of DeBondt and Thaler $(1985 ; 1987)$ and Chen, Lee, and Shih (2016) respectively for evaluating both long-term and short-term contrarian effects in PSX. The study adopts the buy-and-hold method and j-k overlapping portfolio formation procedure to test the long-term and short-term contrarian effects. These methods are considered more practical and provide evidence with more detailed dynamic information than the other traditional methods. Moreover, the study is also carried out to investigate the relation between the performance of contrarian portfolios and several market conditions to further test if the time-varying contrarian effects are context-dependent. The rationale behind using these methodologies is straightforward i.e. to make this study comparable with other studies.

\subsubsection{Non-overlapping Moving Window Analysis}

For long-term contrarian strategy formation, by following the buy-and-hold method, the winner and loser portfolios are formed through monthly Cumulative Average Returns (CARs) of all the stocks. Based on past CARs, we finalize our winner and loser portfolios by arranging the returns into descending order. The nonoverlapping moving window analysis is performed by using a set window of 5 years, where the first three years (36 months) represent the formation period while the subsequent two years (24 months) denote the testing or holding period. We repeat the analysis four times by using 20 years of data ranging from January 1999 and to December 2018, which contains the formation dates as January 1999, January 2004, January 2009 and January 2014.

In the first step, losers and winners' stocks are identified by comparing the past returns of stocks over 36 months. The portfolios are formed by simply ranking the securities in terms of their past 36-month cumulative average returns. By using a decile strategy, the top 10 stocks are treated as winners (W) stocks and the bottom 10 stocks are treated as losers (L) stocks. The zero investment winners and losers' 
portfolios are formed based on equally weighted ${ }^{[5]}$, full rebalancing ${ }^{[6]}$ and decile strategy ${ }^{[7]}$ techniques of portfolio formation. This formation method is widely accepted and used in many past studies (DeBondt and Thaler, 1985; Conrad and Kaul, 1993). The CAR for every stock is calculated based on the prior 36 months in the following manner:

$$
C A R=\sum_{t=-35}^{0} A R_{i t}
$$

In the second step, both the portfolios of winners and losers are held for the next 24 months to examine the performance of portfolios during the holding period. At the end of each window's holding period (t), the Average Excess Returns (AER) obtained through averaging the chosen stocks, is used to calculate the Cumulative Average Excess Returns (CAERs), where $\mathrm{t}=1 \ldots \ldots 24$ months of holding period.

For Winner Portfolio

$$
\begin{array}{ll}
A E R_{w_{s} t}=\frac{1}{n} \sum_{i=1}^{n} E R_{i t} & A E R_{L, t}=\frac{1}{n} \sum_{i=1}^{n} E R_{i t} \\
C A E R_{w, t}=\sum_{t=1}^{24} A E R_{w, t} & C A E R_{L, t}=\sum_{t=1}^{24} A E R_{L, t}
\end{array}
$$

where

$$
\begin{aligned}
& \mathrm{n}=\text { no. of stocks in each portfolio; } \\
& \mathrm{ER}_{\mathrm{it}}=\text { Excess Return of Stock } \mathrm{i} \text { at time } \mathrm{t} .
\end{aligned}
$$

$$
E R_{i t}=R_{i t}-R_{m t}
$$

Excess returns represent the return on investment above than a benchmark or index with a comparable level of risk from a security or portfolio. It is commonly treated as a measure of the value added by an investment manager, or portfolio or the ability of the manager to "beat the market." In general, we use monthly CAERs, where the

\footnotetext{
${ }^{[5]}$ The portfolio formation technique where stocks are added without considering their market capitalization.

${ }^{[6]}$ Portfolios are reshaped or balanced at the end of overall analysis period.

${ }^{[7]}$ The literature suggests two methods i.e. Decile strategy and WRSS for ranking the stocks in each portfolio (loser's portfolio and winner portfolio). In Weighted Relative Strength Strategy (WRSS), stocks are ranked by comparing the performance of a stock with a sample average performance. Weight of every asset is calculated in the following manner:
}

$W_{i}= \pm \frac{1}{N}\left(R_{i}-A R\right)$

Where: $W_{i}=$ weight of security $I, A R=$ the average return of all the samples (Arithmetic Mean), $R_{i}=$ Return of evaluated asset, $N=$ the number of stocks in entire sample. 
excess return is $E \boldsymbol{R}_{i t}=\boldsymbol{R}_{i t}-\boldsymbol{R}_{m t}$, and $\mathrm{R}_{\mathrm{it}}$ represents the return of stock $\mathrm{i}$ at time $\mathrm{t}$ and $\mathrm{R}_{\mathrm{mt}}$ is the returns of the market at time t. After the holding period of 24 months, the CAERs of these portfolios show that whether the contrarian effect holds or not for each of the 4 independent event windows. The contrarian effect holds if the following equation of stock market overreaction fulfills:

$$
t>0 \operatorname{CAER}_{W, t}<0 \quad \& \quad t>C A E R_{L, t}>0 \Rightarrow\left(C A E R_{L, t}-C A E R_{W, t}\right)>0
$$

\subsubsection{Contrarian Strategy with Monthly Re-balancing}

After verifying the presence of long-term contrarian effect, the research then moves to analyze the short-term contrarian effect in PSX. To fulfill this purpose, the research forms the overlapping portfolios with monthly rebalancing by following Jegadeesh and Titman (1993) and Chen et al. (2016). Monthly returns of all the selected stocks are utilized to categorize the winner and loser stocks at the end of every month. Based on the pas twelve months' CARs, the stocks are sorted into winners and losers' portfolios at the end of each month (t). The stocks with past cumulative average returns in the top (bottom) $20 \%$ during the formation period ( $\mathrm{t}$ 12) to month (t-1) are arranged into winners (loser) portfolios.

$$
C A R=\sum_{t=-12}^{-1} A R_{i t}
$$

By following Asness (1994), we implement contrarian strategies with the one-month delay between the formation and holding periods to avoid issues related to microstructure such as liquidity biases, trading costs and bid-ask spread. After constructing the equally weighted winners and loser portfolios at the end of each month $(\mathrm{t})$, we further calculate the subsequent month's $(\mathrm{t}+1)$ holding period returns for each portfolio. By assuming the contrarian strategy of having a long (short) position in loser (winner) stocks with monthly rebalancing, we calculate the monthly contrarian payoffs (LMW), which is the return spread between the equally weighted loser and winner portfolio over $(\mathrm{t}+1)$ month holding period.

$$
L M W_{t}=Q_{L, t}-Q_{W, t}>0
$$

The market risk-adjusted contrarian returns are the CAPM alpha $(\alpha)$ and calculated using the following equation:

$$
L M W_{t}-R_{f, t}=\alpha+\beta\left(R_{m, t}-R_{f, t}\right)+\varepsilon_{t}
$$

where,

$\mathrm{LMW}_{\mathrm{t}}=$ return on contrarian portfolio at month $\mathrm{t}$;

$\mathrm{R}_{\mathrm{f}, \mathrm{t}}=$ risk-free rate at month $\mathrm{t}$;

$\beta=$ beta for contrarian portfolio;

$\mathrm{R}_{\mathrm{m}, \mathrm{t}}=$ market return at month $\mathrm{t}$. 
Having calculated the monthly time-series of contrarian returns, the research further examines the behavior of contrarian returns under time-varying market states and volatility. By following Wang and $\mathrm{Xu}$ (2015), the market state is measured as the past 12-month returns on the value-weighted index of the market at time t. For example, a month will be in a POSITIVE (NEGATIVE) market state if the past 12 month return on market index is positive (negative). Similarly, a month will be in HIGH (LOW) volatility state if the past 6-month volatility of the market index is greater (smaller) than the past 12-month index volatility. To capture the possible effect of the Asian financial crisis and Global crisis on contrarian returns, we extend the study period for monthly rebalancing analysis from 1997 to 2018 .

\section{Empirical Results and Interpretations}

\subsection{Results for Non-Overlapping Moving Window}

Table 1 provides the descriptive statistics of stocks and portfolios during formation periods. This Table reports the total number of stocks included in each of the four non-overlapping formation windows. It also provides the cumulative average returns of both winner and loser portfolios at the time of portfolio formation. We include 10 stocks in each portfolio based on the past performance of the stocks. While the total number of stocks ranges from 291 in the first replication to 354 in final replication. The winner (loser) portfolios show positive (negative) returns at the start of every formation period.

Table 1. Descriptive Statistics (Portfolio Formation)

\begin{tabular}{|l|l|l|l|l|}
\hline $\begin{array}{l}\text { Formation Period } \\
\text { (monthly) }\end{array}$ & $\begin{array}{l}\text { Winner /loser } \\
\text { stocks in a } \\
\text { portfolio }\end{array}$ & \multicolumn{2}{|l|}{ CAR at formation period } & $\begin{array}{l}\text { Total No. of stocks } \\
\text { at the of } \\
\text { formation period }\end{array}$ \\
\hline & & Loser & Winner & \\
\hline Jan. 1999 - Dec. 2001 & 10 & -0.0526 & 0.0474 & 291 \\
Jan. 2004 - Dec. 2006 & 10 & -0.0304 & 0.0632 & 300 \\
Jan. 2009 - Dec. 2011 & 10 & -0.0292 & 0.0239 & 305 \\
Jan. 2014 - Dec. 2016 & 10 & -0.0120 & 0.1114 & 354 \\
\hline
\end{tabular}

Note: This Table provides the descriptive statistics of stocks in winners and loser portfolios along with their Cummulative Average Returns (CAR) at the time of portfolio formation.

Source: Authors' calculations.

Table 2 presents the returns of contrarian portfolios (LMW) for all the four independent replications. In the first replication, the contrarian return which is the difference in CAERs between the loser and winner portfolios (CAERL, $24-$ CAERW, 24) is $6.11 \%$ with a p-value of 0.001 . The results are statistically significant at $1 \%$ significance level. Over the holding period of twenty-four months, the loser portfolio outperforms the winner portfolio by $5.8 \%$ in the first replication, while the return of winner portfolios is also negative $(\mathrm{CAERW}<0)$. These results indicate an overreaction of stock prices in portfolios, as the higher returns of 
contrarian portfolios (LMW) are primarily due to the negative (positive) returns of past winner (loser) stocks.

Table 2. Non-overlapping moving window analysis (Full Sample)

\begin{tabular}{|l|l|l|l|l|l|}
\hline \multirow{2}{*}{$\begin{array}{l}\text { Replication } \\
\text { S }\end{array}$} & $\begin{array}{l}\text { Average } \\
\text { number } \\
\text { stocks }\end{array}$ & $\begin{array}{l}\text { CAER at the end of holding } \\
\text { period }\end{array}$ & \multicolumn{2}{l|}{$\begin{array}{l}\text { Difference in CAER between the } \\
\text { Loser and Winners (LMW) at the } \\
\text { end of holding period }\end{array}$} \\
\cline { 2 - 6 } & Winner & Loser & After 24 Months & p-value \\
\hline 1 & 10 & -0.0035 & 0.0575 & 0.0611 & $(0.001) * * *$ \\
\hline 2 & 10 & -0.0024 & 0.0075 & 0.0099 & $(0.343)$ \\
\hline 3 & 10 & -0.0074 & 0.0091 & 0.0166 & $(0.047) * *$ \\
\hline 4 & 10 & -0.0145 & 0.0046 & 0.0191 & $(0.067) *$ \\
\hline
\end{tabular}

Notes: This table provides the cumulative average excess returns (CAER) of winners, losers and contrarian $(L M W)$ portfolios at the end of the holding period. For hypothesis testing, we have used the independent sample t-test for differences about two means. For the significance test of mean differences in investment performance, we used the pooled estimation of variances technique in CAER $t_{\text {. }}$ In parentheses are the p-values for the t-test. Level of significance: $* * * p<0.01, * * p<0.05, * p<0.1$

Source: Authors' calculations.

The contrarian strategy yields positive returns in second, third and fourth replication as well (see table 2). However, the results are significant in replication 3 and 4 only, at $5 \%$ and $10 \%$ significance levels, respectively. Figure 2 presents the movements of CAER for loser and winner stocks over the holding period of $1^{\text {st }}$ replication. The loser stocks consistently outperform their counterparts over the 24-month holding period. The presence of statistically significant contrarian returns due to the overreaction phenomenon rejects the argument of the efficient market hypothesis and proves that PSX is inefficient in its weak form. These findings are consistent with the results of previous studies in the literature. DeBondt and Thaler (1985) found $24.6 \%$ while Clements, Drew, Reedman, and Veeraraghavan (2009) show $53.7 \%$ excess returns of loser's portfolio. The difference in returns between current and previous studies could be associated with different market characteristics and changed study periods. The previous two studies relate to the US equity market from the period 1976 to 2008 , which was relatively a high growth period for US stock market. The higher returns of these studies could be attributed to higher growth rate of the stock market during these study periods.

\subsection{Sub-period Holding Analysis}

In line with existing literature, we perform the sub-period holding analysis to provide more insights about the existence of the contrarian effect. For this purpose, we analyze the returns of portfolios based on sub-period holding analysis by using 7 different strategies. This analysis sub-divides the holding period into 7 different testing periods (e.g., 6 months, 12 Months, 13 Months, 18 Months, 24 Months, 25 Months and 36 Months). There are two main purposes for this division of time. The first is to check whether the contrarian effect also holds in the short-term horizon or 
it is just a long-term phenomenon as claimed by Jegadeesh and Titman (1993). They argue that the overreaction usually occurs either in the second or third year of the holding period. Secondly, the results of this analysis would reveal whether the wellknown January anomaly affects the stock returns. The January effect states that most of the returns occur in January due to the tax-shield effect.

Figure 2. 24-Months CAER of 10 stocks each in winners and losers portfolios $\left(1^{\text {st }}\right.$ replication)

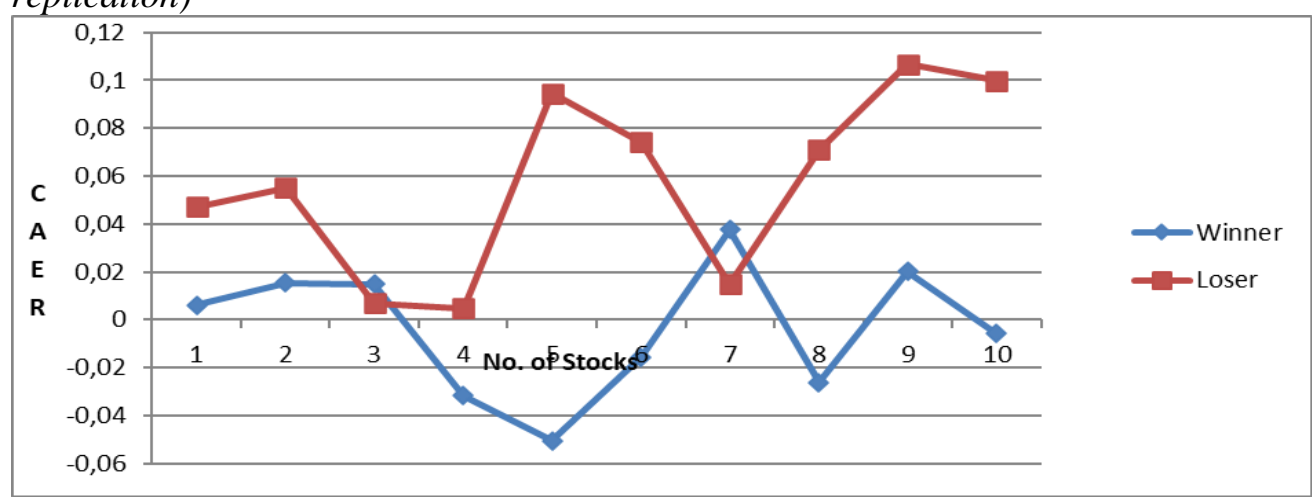

Source: Authors.

Table 3. Sub-period holding analysis (Replication 1)

\begin{tabular}{|l|l|l|l|l|l|l|l|l|l|l|}
\hline $\begin{array}{l}\text { Replic } \\
\text { ations }\end{array}$ & $\begin{array}{l}\text { Av } \\
\text { gno } \\
\text { of } \\
\begin{array}{l}\text { Sto } \\
\text { cks }\end{array}\end{array}$ & $\begin{array}{l}\text { CAER at the end } \\
\text { of formation } \\
\text { period }\end{array}$ & \multicolumn{2}{l|}{$\begin{array}{l}\text { Difference in CAER } \\
\text { (p-value in parentheses) }\end{array}$} \\
\hline & & W & L & 6 & 12 & 13 & 18 & 24 & 25 & 36 \\
\hline $1999-$ & 10 & 0.047 & -0.052 & 0.144 & 0.060 & 0.057 & 0.087 & 0.061 & 0.066 & 0.051 \\
\cline { 2 - 10 } & & & $\begin{array}{l}(0.006) \\
\text { M** }\end{array}$ & $\begin{array}{l}(0.023) \\
* *\end{array}$ & $\begin{array}{l}(0.027) \\
* *\end{array}$ & $\begin{array}{l}(0.000) \\
* * *\end{array}$ & $\begin{array}{l}(0.001) \\
* * *\end{array}$ & $\begin{array}{l}(0.000) \\
* * *\end{array}$ & $\begin{array}{l}(0.000) \\
* * *\end{array}$ \\
\hline
\end{tabular}

Notes: Level of significance: $* * * p<0.01, * * p<0.05, * p<0.1$

Source: Authors' calculations.

Table 3 and Figure 3 present the results of the sub-period holding analysis for the first replication. There are some notable facts in the findings of these analyses. First, the effect of overreaction is symmetric and buy-and-hold contrarian strategy consistently outperforms in both short- and long-term time horizons. The difference of cumulative average excess returns between the loser and winner portfolios is positive in all but significant in most of the cases. Second, the results do not confirm the seasonality effect as the differences in CAER for months $t=13$ and $t=25$, respectively, $5.7 \%$ (p-value: 0.027 ) and $6.64 \%$ (p-value: 0.000 ) are less than the returns earned in other periods during the year i.e. $\mathrm{t}=6$ and $\mathrm{t}=18$, respectively, $14.4 \%$ (0.006) and $8.77 \%(0.000)$. Furthermore, Table 4 provides a more detailed analysis of the same strategy based on the other three independent replications. The results of table 4 again confirm the existence of the contrarian effect in all the remaining replications when analyzed based on sub-period holdings. The overall results of 
long-period holding and sub-period holding analyses imply that PSX is not efficient in its weak-form, while these results are in agreement with the findings of Rouwenhorst (1999), Griffin et al. (2003), Chui, Titman, and Wei (2010). Griffin et al. (2003) study the momentum effect internationally in the following regions: Asia, Europe, Africa, and the United States. They found the momentum effect in almost all the regions except Asia which usually shows the contrarian effect rather than momentum; aligned with the findings of Chui et al. (2010).

Figure 3. Performance of Winners and Losers Portfolios in sub-holding periods (6, $12,13,18,24,25$ and 26 months)

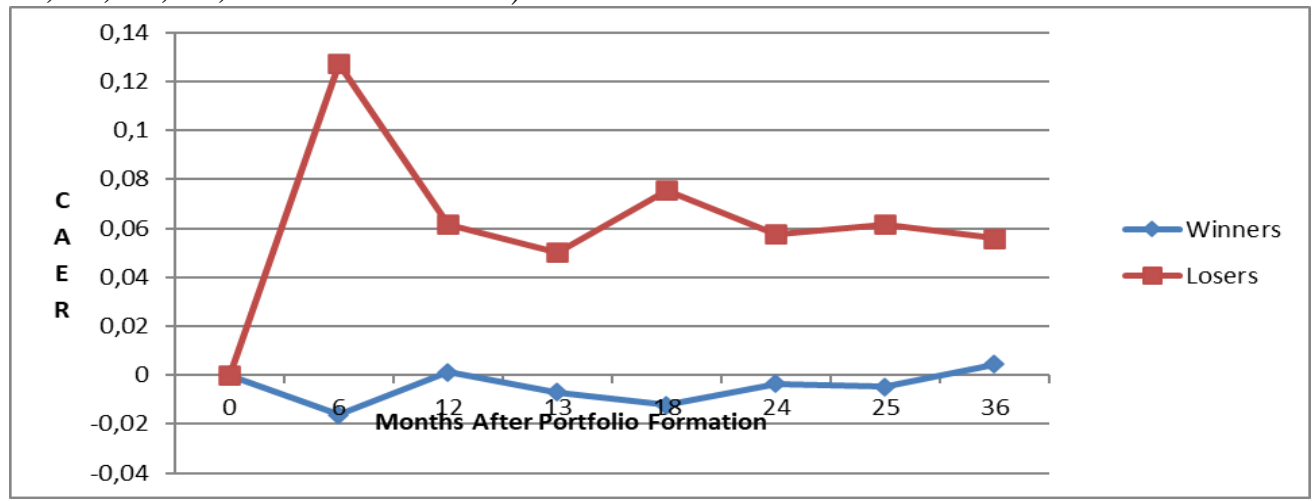

Source: Authors.

Table 4. Sub-period holding analysis (Replication 2-4)

\begin{tabular}{|c|c|c|c|c|c|c|c|c|c|c|}
\hline \multirow[t]{2}{*}{$\begin{array}{l}\text { Replicat } \\
\text { ions }\end{array}$} & \multirow{2}{*}{$\begin{array}{l}\text { Av } \\
\mathrm{g} . \\
\text { nu } \\
\mathrm{mb} \\
\mathrm{er} \\
\text { of } \\
\text { Sto } \\
\text { cks }\end{array}$} & \multicolumn{2}{|c|}{$\begin{array}{l}\text { CAER at the end of } \\
\text { formation period }\end{array}$} & \multicolumn{7}{|c|}{$\begin{array}{l}\text { Difference in CAER } \\
\text { (p-value in parentheses) }\end{array}$} \\
\hline & & Winner & Loser & 6 & 12 & 13 & 18 & 24 & 25 & 36 \\
\hline \multirow{2}{*}{$\begin{array}{l}2004 \\
2008\end{array}$} & \multirow[t]{2}{*}{10} & 0.06328 & 0.03048 & 0.0177 & 0.0186 & 0.017 & 0.0111 & 0.0102 & 0.0115 & 0.0098 \\
\hline & & & & $(0.584)$ & $(0.387)$ & $(0.38)$ & $(0.432)$ & $(0.346)$ & $(0.250)$ & $(0.18)$ \\
\hline \multirow{2}{*}{$\begin{array}{l}2009 \\
2013\end{array}$} & \multirow[t]{2}{*}{10} & 0.02395 & 0.03470 & 0.0401 & 0.0310 & 0.029 & 0.0207 & 0.0171 & 0.034 & 0.045 \\
\hline & & & & $(0.06)^{*}$ & $(0.111)$ & $(0.10)^{*}$ & $(0.109)$ & $(0.09)^{*}$ & $(0.04)^{* * *}$ & $(0.03)^{* * *}$ \\
\hline \multirow{2}{*}{$\begin{array}{l}2014 \\
2018\end{array}$} & \multirow[t]{2}{*}{10} & 0.01114 & -0.0193 & -0.164 & 0.0192 & 0.0049 & 0.0094 & 0.0207 & N/A & N/A \\
\hline & & & & $(0.55)$ & $(0.06)^{*}$ & $(0.32)$ & $(0.61)$ & $(0.06)^{*}$ & & \\
\hline
\end{tabular}

Notes: Level of significance: $* * * p<0.01$, ** $p<0.05, * p<0.1$. N/A represents the periods beyond the study period

Source: Authors' calculations.

\subsection{Effects of Changed Market Conditions on Monthly Contrarian Payoffs}

Having verified the existence of long-term contrarian profits, the research moves to calculate the monthly time-series of contrarian payoffs and further tests the impact of changed market conditions on contrarian profitability. For this analysis, we extend the study period from January 1997 to December 2018. The motivation of this 
extended sample period is the inclusion of two major crises (e.g., Asian Financial Crisis and the Global Crisis). The preliminary findings of this sub-section again confirm the presence of a statistically significant contrarian effect with the monthly rebalancing of contrarian strategy in PSX. Table 5 provides the contrarian strategy returns during the full sample and crisis periods sub-samples. The mean raw (riskadjusted) contrarian (LMW) returns are positive with $0.82 \%$ (0.36\%). Interestingly, the contrarian strategies yield significantly higher mean raw (risk-adjusted) returns during crisis periods, more than twice that of the non-crisis periods such as $2.81 \%$ $(1.95 \%)$. One possible explanation for contrarian profitability during the crash periods could be that the investors search for the safe heavens during these periods and flock to higher quality (winner) stocks that have higher credit ratings.

Moreover, the widespread pessimism towards loser stocks drives down their prices too low which exaggerates the risks and reduces the chances of returns to these stocks. Subsequently, the loser stocks outperform when the market rebounds and corrects the prices of overpriced and underpriced stocks. Thus, the strategy of purchasing these distressed stocks at lower prices and selling when they recover leads to significant future returns. These findings are consistent with recent research of Daniel and Moskowitz (2016), where they state that the momentum strategy crashes, particularly during panic states and higher market volatility states.

Table 5. Profitability of the contrarian strategy with monthly rebalancing

\begin{tabular}{|c|c|c|c|}
\hline \multicolumn{4}{|c|}{ Full sample (January 1, 1997 - December 31, 2018) } \\
\hline & Winner & Loser & Contrarian (LMW) \\
\hline \multirow{2}{*}{ Mean return } & $4.003 * * *$ & $4.821 * * *$ & $0.827 * * *$ \\
\hline & (7.79) & (6.84) & (3.59) \\
\hline \multirow[t]{2}{*}{ Risk-adjusted return } & $2.913 * * *$ & $3.443 * * *$ & $0.365 * * *$ \\
\hline & $(6.22)$ & (7.77) & (2.70) \\
\hline \multicolumn{4}{|c|}{ Panel B: Crisis Periods (Jan. 1998 - Dec. 1999 and Oct. 2007 - Sep. 2009) } \\
\hline Mean return & $\begin{array}{l}1.504 * * * \\
(3.06)\end{array}$ & $\begin{array}{l}4.489 * * * \\
(5.38)\end{array}$ & $\begin{array}{l}2.810 * * * \\
(3.76)\end{array}$ \\
\hline Risk-adjusted return & $\begin{array}{l}1.948 * * \\
(2.24)\end{array}$ & $\begin{array}{l}4.188 * * * \\
(4.93)\end{array}$ & $\begin{array}{l}1.959 * \\
(1.69)\end{array}$ \\
\hline
\end{tabular}

Notes: This table presents the results of the contrarian strategy returns with monthly rebalancing. Panel A provides the results of the overall sample period, while Panel B reports the contrarian returns during the crisis months (i.e. Asian financial Crisis from Jan. 1998 to Dec. 1999 and global crisis from Oct. 2007 to Sep. 2009). Based on the prior twelve months' returns, the stocks are sorted into winners and losers' portfolios at the end of every month $(t)$. The stocks with positive (negative) past cumulative average returns over the formation period (t-12) to month (t-1) are arranged into loser and winner portfolios. Contrarian returns are the subsequent holding period $(t+1)$ returns computed as the return spread between the loser and winner portfolios (LMW). Risk-adjusted profits are CAPM-alpha. The returns are expressed in percentage points. In parentheses are the values of $t$-statistic. *, ** and *** represent the level of significance at 10,5 and 1 percent, respectively.

Source: Authors calculations.

Having verified the existence of a contrarian effect and preliminary indications of the time-varying behavior of contrarian payoffs, the research further examines the 
pattern of contrarian payoffs under varying market states (POSITIVE/NEGATIVE) along with volatility (HIGH/LOW) clustering across each market state. To accomplish this objective, we divided the entire months of study period into four categories across the pairs of market state and volatility. As earlier stated, a month will be in a POSITIVE (NEGATIVE) market state if the past 12-month return on market index is positive (negative). Each market state (POSITIVE, NEGATIVE) is further subdivided into HIGH (LOW) volatility subgroups. The market in a month will be considered as the HIGH (LOW) volatility state if the past 6-month market index volatility is greater (smaller) than the past 12-month index volatility. Table 6 presents the mean raw (risk-adjusted) contrarian returns of all the four likely combinations of market state and volatility. As our study period covers 264 months, out of these, PSX is in a positive (negative) state in 198 (66) months. Within a positive market state, the months in high (low) volatility for PSX are 80 (118). Similarly, the months of high (low) volatility in the negative market state are 24 (42).

The analysis of the contrarian payoffs shown in Table 6 indicates that both the state of the market and the volatility matter in contrarian profitability. However, the higher mean and risk-adjusted payoffs to contrarian strategy are observed in the negative market state with higher volatilities. The mean return difference between the negative and positive market states with higher volatility is as large as $6.78 \%$ (6.958-0.175). If we compare the volatility factor across each market state, we observe that the higher volatility months outperform the lower volatility months, but the results are not significant. This important finding implies that the market state effect is more dominant as compared to the market volatility effect. Moreover, this finding contradicts the results of Wang and $\mathrm{Xu}$ (2015), who find that the volatility factor absorbs most of the explanatory power for momentum payoffs in a more developed US market. From an investment perspective, we can conclude that higher contrarian returns can be generated by forming portfolios in negative and higher market volatility states.

Table 6. Market State, Volatility and Contrarian Strategy Payoffs

\begin{tabular}{|c|c|c|c|c|}
\hline & \multicolumn{2}{|c|}{ POSITIVE Market State } & \multicolumn{2}{|c|}{ NEGATIVE Market State } \\
\hline & High Volatility & Low Volatility & High Volatility & Low Volatility \\
\hline \multirow[t]{2}{*}{ Mean return } & 0.175 & 0.143 & $6.958 * *$ & 1.322 \\
\hline & $(0.23)$ & $(0.09)$ & $(2.3)$ & $(1.52)$ \\
\hline \multirow[t]{2}{*}{ Risk-Adjusted return } & 0.114 & 0.015 & $4.955 * *$ & $1.462 *$ \\
\hline & $(0.15)$ & $(0.02)$ & $(2.23)$ & $(1.7)$ \\
\hline No. of months & 80 & 118 & 24 & 42 \\
\hline
\end{tabular}

Notes: This table provides the impact of varying market states on contrarian payoffs. Based on the prior twelve months' returns, the stocks are sorted into winners and losers' portfolios at the end of every month $(t)$. The stocks with positive (negative) past cumulative average returns during the formation period of $(t-12)$ to $(t-1)$ are arranged into the portfolios of winners (loser). Contrarian returns are the subsequent holding period $(t+1)$ returns computed as the return spread between the loser and winner portfolios (LMW). The market in any month will be in a POSITIVE (NEGATIVE) market state if the past 12-month market index return is positive (negative). The market in any month will be considered in the HIGH 
(LOW) volatility state if the past 6-month volatility of the market index is greater (smaller) than the past 12-month index volatility. Risk-adjusted profits are CAPM-alpha. The returns are expressed in percentage points. In parentheses are the values of $t$-statistic. *,** and *** represent the level of significance at 10, 5 and 1 percent, respectively.

Source. Authors' calculations.

The time-varying pattern of contrarian payoffs under the changed market conditions is somewhat observable in Figure 4 as well. We can observe the clusters of higher contrarian payoffs under the negative conditions of PSX, particularly during the period of Asian crisis from Jan 1998 to December 1999, then in beginning-2001 through 2002, in the first half of 2012 and later during the period of global crisis where there are notable positive spikes in contrarian payoffs. The study period from 2000 to 2005 is very unique for the Pakistan stock exchange as the market faced two notable manipulative bubbles during this period (Khwaja and Mian, 2005; Azad et al., 2014). Due to pump-and-dump or trade-induced manipulations by market intermediaries in PSX, the stock market index fell by almost $19 \%$ alone in May $2000^{[8]}$. A similar incident occurred in March 2005, where the entire market index fell by almost 25\%. Both the crashes of May 2000 and March 2005 had been subject to a criminal inquiry. Furthermore, during the financial year 2011 to 2013, the stock market reacted dramatically by exhibiting unexpected phases of bubbles and sudden crashes during this period.

Figure 4. Market State and Contrarian payoffs (LMW) in Pakistan

\section{Market State}

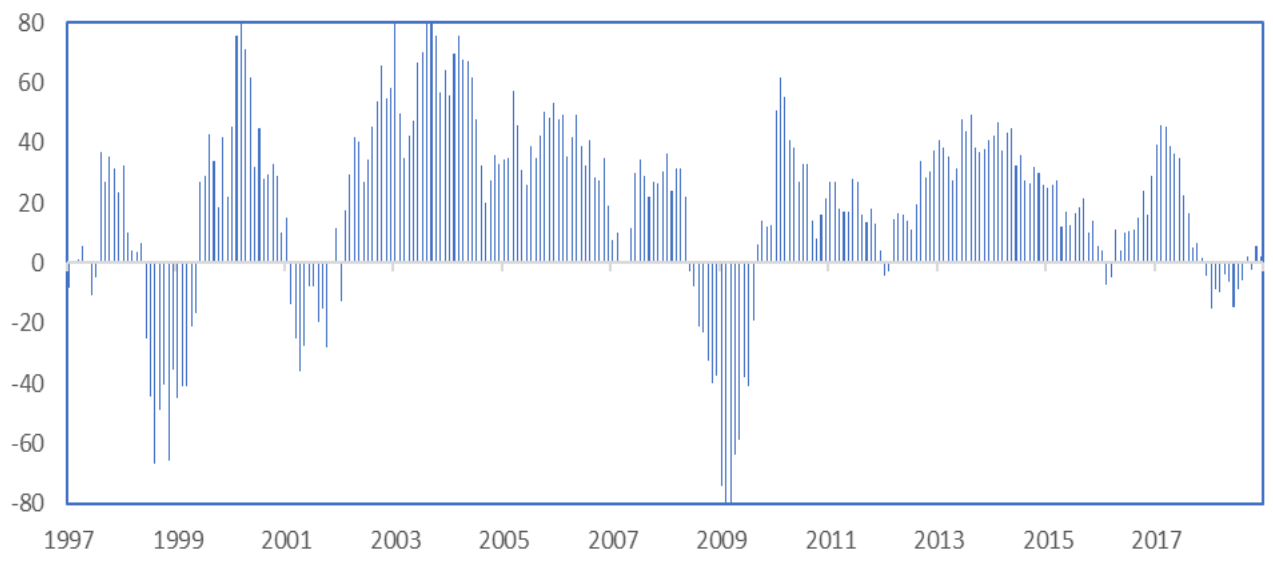

${ }^{[8]}$ Business Recorder: June 24, 2007 


\section{Contrarian Payoffs (LMW)}

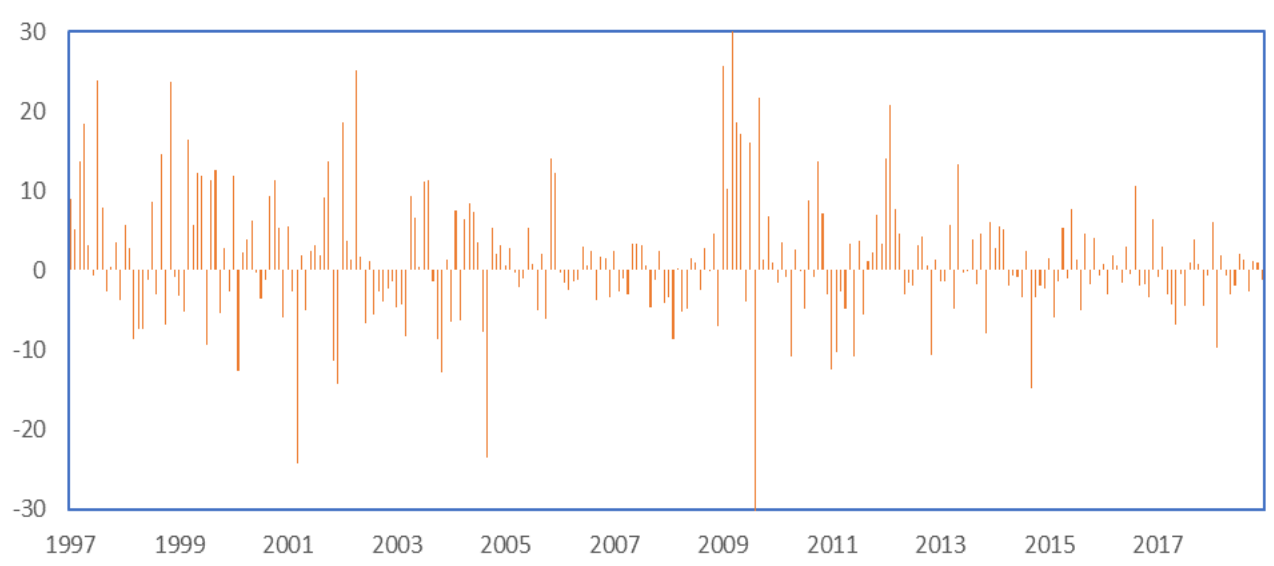

Source: Authors' calculations.

As per the results of this study based on two different perspectives, contrarian profitability is highly dependent on time-varying market conditions. Higher contrarian profits are associated with crisis periods, negative market state and higher market volatility. The magnitude of the changes in contrarian profits during different market conditions supports the existence of the AMH in PSX. According to the $\mathrm{AMH}$, the level of market efficiency varies over time due to the changed macrofactors of a financial market (Lo, 2012).

\section{Conclusion}

In this study, we focus on testing the various patterns of contrarian trading scheme that can generate superior returns for retail investors in Pakistan stock Exchange. We analyze the long-term buy-and-hold method and short-term overlapping portfolio formation procedures for evaluating the contrarian effects. Moreover, the research is also carried out to test the possible effect of stock market conditions on contrarian profitability for testing some implications from the Adaptive Market Hypothesis.

The empirical findings suggest the existence of both long-term and short-term reversal effects. During the buy-and-hold analysis, the mean differences of cumulative average excess returns (CAER) between the loser and winner portfolios are positive in all the testing windows. The results are significant in most of the cases at either $1 \%, 5 \%$, or $10 \%$ significance levels. Moreover, the results are robust under the sub-period holding analysis as well. We analyze the returns of winner and loser portfolios based on sub-period holding analysis by using 7 different strategies within each window. The difference of CAER between the loser and winner portfolios are again positive in all but significant in most of the sub-holding periods. The results confirm the non-existence of the impact of seasonality / January anomaly 
on contrarian returns. The overall results of buy-and-hold and sub-period holding analyses are in agreement with the findings of existing researches (Rouwenhorst, 1999; Griffin et al., 2003; Chui et al., 2010).

The study findings based on overlapping portfolio analysis with monthly rebalancing reveal that contrarian strategies yield higher returns during crisis periods, negative market state and higher market volatility. However, the market state effect is more dominant as compared to the market volatility effect. From an investment perspective, we conclude that higher contrarian returns can be generated in PSX by forming portfolios in negative market states with higher volatility. The overall findings of current research regarding the time-variation in contrarian payoffs and the possible market state effect on contrarian profitability offer partial support to the Adaptive Market Hypothesis (AMH), which claims that the changed market conditions are the main causes of time-varying market efficiency.

However, another important finding of this research implies that the investors from PSX may not adapt to the changing market conditions like the investors in developed markets, therefore, the contrarian profits always exist, and the consistent weak form market inefficiencies prevail in PSX. Future research can provide more insights by examining the explanatory role of macroeconomic variables and global risk proxies towards contrarian payoffs. Moreover, the studies could find out the specific periods of stock market manipulations in various South-Asian emerging markets and examine which of the trading schemes (contrarian or momentum) generates superior returns under different phases of stock market manipulations.

\section{References:}

Asness, C.S. 1994. Variables that explain stock returns. Pd.D. Dissertation, University of Chicago.

Asness, C.S., Frazzini, A., Israel, R., Moskowitz, T. 2015. Fact, fiction, and value investing. The Journal of Portfolio Management, 42(1), 34-52.

Asness, C.S., Moskowitz, T.J., Pedersen, L.H. 2013. Value and momentum everywhere. The Journal of Finance, 68(3), 929-985.

Azad, A.S.M.S., Azmat, S., Fang, V., Edirisuriya, P. 2014. Unchecked manipulations, pricevolume relationship and market efficiency: Evidence from emerging markets.

Research in International Business and Finance, 30, 51-71.

Bernstein, S., Lerner, J., Schoar, A. 2013. The investment strategies of sovereign wealth funds. Journal of Economic Perspectives, 27(2), 219-238.

Chen, H.Y., Lee, C.F., Shih, W.K. 2016. Technical, fundamental, and combined information for separating winners from losers. Pacific-Basin Finance Journal, 39, 224-242.

Chui, A.C., Titman, S., Wei, K.C. 2010. Individualism and Momentum around the World. The Journal of Finance, 65(1), 361-392.

Chui, A.C., Wei, K.C., Titman, S. 2000. Momentum, legal systems and ownership structure: An analysis of Asian stock markets. Sheridan, Momentum, Legal Systems and Ownership Structure: An Analysis of Asian Stock Markets. 
Clements, A., Drew, M.E., Reedman, E.M., Veeraraghavan, M. 2009. The death of the overreaction anomaly? A multifactor explanation of contrarian returns. Investment Management and Financial Innovations, 6(1), 76-85.

Conrad, J., Kaul, G. 1993. Long-Term Market Overreaction or Biases in Computed Returns? The Journal of Finance, 48(1), 39-63.

Cooper, M.J., Gutierrez, R.C., Hameed, A. 2004. Market States and Momentum. The Journal of Finance, 59(3), 1345-1365.

Cuthbertson, K., Nitzsche, D. 2005. Quantitative financial economics: stocks, bonds and foreign exchange. John Wiley \& Sons.

Daniel, K., Moskowitz, T.J. 2016. Momentum crashes. Journal of Financial Economics, 122(2), 221-247.

De Haan, L., Kakes, J. 2011. Momentum or contrarian investment strategies: Evidence from Dutch institutional investors. Journal of Banking \& Finance, 35(9), 2245-2251.

DeBondt, W.F.M., Thaler, R. 1985. Does the stock market overreact? The Journal of Finance, 40(3), 793-805.

DeBondt, W.F.M., Thaler, R. 1987. Further evidence on investor overreaction and stock market seasonality. The Journal of Finance, 42(3), 557-581.

Doan, M.P., Alexeev, V., Brooks, R. 2014. Concurrent momentum and contrarian strategies in the Australian stock market. Australian Journal of Management, 41(1), 77-106.

Fama, E.F., French, K.R. 2008. Dissecting Anomalies. The Journal of Finance, 63(4), 16531678.

Fama, E.F., French, K.R. 2012. Size, value, and momentum in international stock returns. Journal of Financial Economics, 105(3), 457-472.

Glaeser, E., Johnson, S., Shleifer, A. 2001. Coase versus the coasians. The Quarterly Journal of Economics, 116(3), 853-899.

Griffin, J.M., Ji, X., Martin, J.S. 2003. Momentum investing and business cycle risk: Evidence from pole to pole. Journal of Finance, 58(6), 2515-2547.

Grinblatt, M., Moskowitz, T.J. 2004. Predicting stock price movements from past returns: the role of consistency and tax-loss selling. Journal of Financial Economics, 71(3), 541579.

Grundy, B.D., Martin, J.S.M. 2001. Understanding the nature of the risks and the source of the rewards to momentum investing. The Review of Financial Studies, 14(1), 29-78.

Hameed, A., Ting, S. 2000. Trading volume and short-horizon contrarian profits: Evidence from the Malaysian market. Pacific-Basin Finance Journal, 8(1), 67-84.

Hart, Slagter, E., Dijk, D. 2003. Stock selection strategies in emerging markets. Journal of Empirical Finance, 10(1), 105-132.

Harvey, C.R. 1995. Predictable Risk and Returns in Emerging Markets. The Review of Financial Studies, 8(3), 773-816.

Huang. 2006. Market states and international momentum strategies. The Quarterly Review of Economics and Finance, 46(3), 437-446.

Jegadeesh, N., Titman, S. 1993. Returns to buying winners and selling losers - implications for stock-market efficiency. Journal of Finance, 48(1), 65-91.

Khwaja, A.I., Mian, A. 2005. Unchecked intermediaries: Price manipulation in an emerging stock market. Journal of Financial Economics, 78(1), 203-241.

La Porta, R., Lopez-De-Silanes, F., Shleifer, A. 2006. What works in securities laws? The Journal of Finance, 61(1), 1-32.

Lewellen, J. 2002. Momentum and Autocorrelation in Stock Returns. The Review of Financial Studies, 15(2), 533-564. 
Lo, A.W. 2004. The Adaptive Markets Hypothesis. The Journal of Portfolio Management, $30(5), 15$.

Lo, A.W., MacKinlay, A.C. 1988. Stock market prices do not follow random walks:

Evidence from a simple specification test. The Review of Financial Studies, 1(1), 41-66.

Locke, S., Gupta, K. 2009. Applicability of contrarian strategy in the bombay stock exchange. Journal of Emerging Market Finance, 8(2), 165-189.

Malkiel, B.G. 2003. The efficient market hypothesis and its critics. Journal of Economic Perspectives, 17(1), 59-82.

Meier, C. 2014. Adaptive market efficiency: review of recent empirical evidence on the persistence of stock market anomalies. Review of Integrative Business and Economics Research, 3(2), 268.

Muga, L., Santamaría, R. 2007. The momentum effect in Latin American emerging markets. Emerging Markets Finance and Trade, 43(4), 24-45.

Parhizgari, A.M., Nguyen, D. 2008. ADRs under momentum and contrarian strategies. Global Finance Journal, 19(2), 102-122.

Ramiah, V., Cheng, K.Y., Orriols, J., Naughton, T., Hallahan, T. 2011. Contrarian investment strategies work better for dually-traded stocks: Evidence from Hong Kong. Pacific-Basin Finance Journal, 19(1), 140-156.

Rouwenhorst, K.G. 1998. International Momentum Strategies. The Journal of Finance, 53(1), 267-284.

Rouwenhorst, K.G. 1999. Local return factors and turnover in emerging stock markets. The Journal of Finance, 54(4), 1439-1464.

Shah, J., Shah, A. 2017. Contrarian and momentum investment strategies in pakistan stock exchange. Available at SSRN 3063904.

Shiller, R.J. 1990. Market volatility and investor behavior. The American Economic Review, 80(2), 58.

Thalassinos, I.E., Thalassinos, E.P. 2006. Stock Markets' Integration Analysis. European Research Studies Journal, 9(3-4), 3-14.

Thalassinos, I.E. Kyriazidis, Th., Thalassinos, E.J. 2006. The Greek Capital Market: Caught in Between Corporate Governance and Market Inefficiency. European Research Studies Journal, 9(1-2), 3-24, DOI: 10.35808/ersj/146.

Thalassinos, I.E., Ugurlu, E. and Muratoglu, Y. 2015. Comparison of Forecasting Volatility in the Czech Republic Stock Market. Applied Economics and Finance, 2(1), 11-18, DOI:10.11114/aef.v2i1.608.

Urquhart, A., McGroarty, F. 2014. Calendar effects, market conditions and the Adaptive Market Hypothesis: Evidence from long-run U.S. data. International Review of Financial Analysis, 35, 154-166.

Wang, K.Q., Xu, J. 2015. Market volatility and momentum. Journal of Empirical Finance, 30, 79-91.

Yu, L., Fung, H.G., Leung, W.K. 2019. Momentum or contrarian trading strategy: Which one works better in the Chinese stock market. International Review of Economics \& Finance, 62, 87-105. 